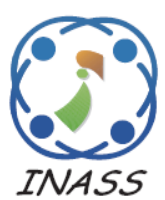

http://www.inass.org/

\title{
Maximum Power Point Tracking Method for Photovoltaic System Based on Enhanced Particle Swarm Optimization Algorithm Under Partial Shading Condition
}

\author{
Anas Abduladheem Kamil ${ }^{1}$ \\ Mahmoud Shaker Nasr ${ }^{2}$ \\ Shamam Alwash ${ }^{1 *}$ \\ ${ }^{I}$ Department of Electrical Engineering, University of Babylon, Babylon, Iraq \\ ${ }^{2}$ Department of Biomedical Engineering, University of Babylon, Babylon, Iraq \\ * Corresponding author's Email: shamamalwash@yahoo.com
}

\begin{abstract}
The maximum power point tracking (MPPT) is an essential key to ensure that the photovoltaic (PV) system is operated at the highest possible power generation. This paper presents an efficient MPPT method for the PV system based on an enhanced particle swarm optimization algorithm to track the location of the global maximum power point, whatever its location changes in the search space under all environmental conditions, including the partial shading on strings. In this paper, the formulation of the conventional particle swarm optimization algorithm is enhanced to decrease the searching time and the oscillation of the generated output power as well as the power losses in the online tracking process. This enhancement can be achieved by utilizing a special time-varying weighting coefficient and removing the effect of some other coefficients in the conventional particle swarm optimization algorithm (PSO) that cause winding of the particles during the online tracking process. Test results verified the accuracy of the proposed method to track the global maximum power point with considering the effect of partial shading condition. The proposed method was also compared with other MPPT methods to verify the superiority of the proposed work. The obtained results reveal that the proposed method is effective to improve the tracking efficiency and reduce the tracking time and the number of iterations for the different irradiances and load conditions. The maximum number of iterations was 11 iteration and the highest tracking time was 0.273 s with tracking efficiency of about $99.98 \%$.
\end{abstract}

Keywords: Enhanced particle swarm optimization, Global maximum power point, Partial shading condition, Photovoltaic system.

\section{Introduction}

The interest in clean energy sources has increased in the last two decades compared to energy sources that depend on fossil fuels, for many reasons like a pollution-free, no-noise, low cost of operation, and maintenance. Photovoltaic (PV) systems are one of the most important renewable energy sources. Recently, PV systems have been widely used in different applications such as large-scale power plants, solar home systems, water pumping stations, space vehicles, satellites, and service reverse osmosis water plants. However, the output generated power of the PV module is variant due to the non-linear characteristics of the module that depends on the solar irradiation, temperature, and load connected.
Thus, to obtain the highest possible power generated under these various conditions, the PV system must enforce to work at the maximum power point (MPP) that can be achieved through the use of maximum power point tracking (MPPT) methods.

Several MPPT methods have been developed to extract the maximum power in the PV system, such as perturbation and observation (P\&O) [1], incremental conductance (IC) [2], fractional short circuit current [3], and fractional open circuit voltage [4]. The behavior of the fractional methods depends on a fixed point related to the open-circuit voltage and the short-circuit current of the PV system, respectively. Practically, these fractional methods cannot achieve the maximum power point generation at all variable conditions $[5,6]$. The $\mathrm{P} \& \mathrm{O}$ and IC 
methods are based on the principle of perturbing of the PV array voltage and observing the output power. According to the values of the voltage and output power in successive steps, the direction toward the MPP (i.e., the peak point on the characteristic of PV array) can be obtained. The main drawbacks of these two methods are oscillation around the peak point and the low tracking speed during rapid changes in environmental conditions [7]. However, all the mentioned methods suffer from inaccuracy to track the global maximum power point (GMPP) under partial shading conditions due to the presence of multiple peaks, which depend on the partial shading conditions and the number of series PV panels in the string [8].

Several methods have been developed to track the MPP with handling the problem of partial shading conditions. In [9], a modified P\&O method has been used to track the MPP under partial shading conditions. In this method, a checking algorithm based on the prior knowledge about the number of series PV panels in the string is used to scan all existing peaks and determine the global one. Therefore, the $\mathrm{P} \& \mathrm{O}$ algorithm is utilized to determine accurate MPP. Although the problem of multiple peaks has been solved, this method still suffers from high oscillation due to the use of the perturbation and observation technique. An MPPT method based on an artificial neural network technique was proposed in [10]. In this method, an expensive solution to the problem of multiple peaks based on utilizing a dc-dc converter for each PV panel in the string was presented. In [11], large steps voltage have been used to scan all peaks in the PV curve and identify the global one assuming that the voltage per step was equal to $75 \%$ of the open-circuit voltage of a single series PV panel whereas the accurate MPP has been determined using a fuzzy logic technique. To avoid the dependency on the prior knowledge about the number of series PV panels in the string, a linear ramp reference voltage along the PV curve has been used in [12] to track an approximate MPP while the exact global point is obtained using the fuzzy logic technique. However, this method suffers from severe oscillation and long tracking time, as well as a high cost due to its requirement for a large number of sensors at the string and load sides.

Recently, many methods based on meta-heuristic techniques have been utilized to track the MPP with considering the problem of partial shading conditions such as Genetic Algorithm (GA) [13], Cuckoo Search (CS) [14], Artificial Bee Colony (ABC) [15], Ant Colony Optimization (ACO) [16], Firefly (FA) [17], Grey Wolf Optimization (GWO) [18], Bat Algorithm (BA) [19], Flower Pollination Algorithm (FPA) [20],
Teaching-learning-based optimization (TLBO) [21] and Particle Swarm Optimization (PSO) [22-24]. These methods were distinguished by their accuracy and high speed in tracking for the maximum power point in all environment conditions. Moreover, these methods were characterized by cheap costs of their implementation, as they do not require equipment to measure the solar radiation falling on PV arrays. However, these methods still compete in achieving low oscillation in the power generated and better accuracy, speed, and responsiveness in tracking the MPP.

Among all aforementioned meta-heuristic techniques, the PSO algorithm has been widely modified to address the problem of the MPPT under partial shading conditions [25-31]. In [25], a MPPT method based on a modified PSO algorithm is developed. In this method, the problem of the initial duty cycle that is generated randomly in the conventional PSO algorithm is avoided by using a deterministic procedure to calculate the initial duty cycle. Although this method reduces the initial oscillation of the output power that occurred with any change in the solar irradiation, it still suffers from high oscillation and long tracking time due to the presence of random parameters in the velocity equation. Also, this method requires an expensive irradiation sensor at each PV string. In [26], a leader PSO algorithm is developed to track the MPP with considering the partial shading conditions. This method utilizes exclusive mutation strategies to increase the search process and to differentiate between local and global MPPs by increasing randomness in particle behaviors. However, the oscillation of the output power is not considered. In [27], an MPPT method based on the overall distribution and PSO algorithms is developed to track the MPP under partial shading conditions using two steps. In the first step, the overall distribution algorithm is used to scan the search space and locate the region of the MPP. However, the conventional PSO algorithm is then used to identify accurate MPP as a second step. A hybrid enhanced leader PSO assisted by a conventional $\mathrm{P} \& \mathrm{O}$ algorithm is proposed in [28]. In this method, the region of the MPP is firstly located using enhanced leader PSO while the accurate MPP is identified using conventional P\&O method. In [29], the region of the MPP is firstly located using an improved PSO algorithm, and then the hill climbing (HC) method with a small disturbance is utilized to identify the accurate MPP. However, the previous two methods presented in [28] and [29] suffer from the oscillation around the peak point (MPP) due to the perturbation and observation processes utilized in $\mathrm{P} \& \mathrm{O}$ and $\mathrm{HC}$ 
methods, respectively. A hybrid method based on the combination of the PSO algorithm and the differential evaluation (DE) algorithm is presented in [30]. In this method, the convergence behavior of the searching particles in the PSO algorithm is improved using the DE algorithm. However, this method still requires a long tracking time (4-5s) to identify the MPP. In [31], the MPPT method based on the Velocity PSO-Lévy Flight (VPSO-LF) algorithm is developed. In this method, the number of tuning parameters of the PSO velocity equation has significantly been minimized using the Lévy Flight concept. This method aims to reduce the random behavior of the particles and thus decrease the searching time and oscillation of the output power. However, the results presented in [31] show the best tracking time $(0.23-0.87 \mathrm{~s}$.).

In this paper, an efficient MPPT method based on an Enhanced Particle Swarm Optimization (EPSO) algorithm is proposed to track the MPP in the PV system with considering the partial shading conditions. The main contribution of the proposed method is to enhance the conventional PSO algorithm based on utilizing the time-varying weighting coefficient and setting the acceleration coefficients to unity in the algorithm. In addition, the proposed method removes the effect of random numbers used in the conventional PSO, which can cause the winding of the particles during the online searching process. The main advantage of the proposed method compared with other existing methods is that the absence of random numbers proposed in this method reduces the searching time, the oscillation of the output power, and the power losses caused by winding of the particles.

The remainder of this paper is organized as follows. Section 2 provides the modeling and characteristics of the photovoltaic array. Section 3 illustrates a conventional PSO algorithm. Section 4 describes the proposed MPPT method based on the EPSO algorithm. Section 5 presents an overview of one of the MPPT meta-heuristic methods. In Section 6 , the obtained results and discussion are provided. Finally, the conclusion is outlined in Section 7.

\section{Modeling and characteristics of PV array}

Generally, the PV array consists of several parallel strings that are built up using series PV panels, as shown in Fig. 1. Each PV panel is produced using one or more modules, which consist of a certain number of PV cells connected in series and parallel according to the voltage and power required. The single diode model of the photovoltaic cell can be represented by the equivalent circuit shown in Fig. 2.
The model comprises a current source $(I)$, a diode, a series resistance $\left(R_{S}\right)$ and shunt resistance $\left(R_{S h}\right)$. The current PV cell $\left(I_{P V}\right)$ represented by the equation below [32]:

$$
\begin{aligned}
& I_{P V}=I-I_{d}-\frac{V_{P V}+\left(I_{P V} \times R_{s}\right)}{R_{s h}} \\
& I_{d}=I_{s} \times\left(\exp \left(\frac{V_{d}}{\alpha \times V_{t h}}\right)-1\right) \\
& V_{t h}=\frac{K \times T_{c}}{q} \\
& I=I_{s c}+K_{1}\left(T_{c}-T_{r e f}\right) \lambda \\
& V_{P V}=V_{d}-I \times R_{S}
\end{aligned}
$$

where $V_{P V}$ is the photovoltaic output voltage, $I_{s}$ represents the diode reverse saturation current, $V_{d}$ is the diode voltage, $V_{t h}$ is the thermal voltage of the diode, $\alpha$ is the ideal factor of a diode, $K$ is Poltzman's constant $(1.38 \mathrm{e}-23 \mathrm{~J} / \mathrm{K}), T_{c}$ is the cell working temperature, $q$ is the electron charge $(1.6 \mathrm{e}-$ $19 \mathrm{C}$ ), $I_{s c}$ is the cell short circuit current (at $25^{\circ} \mathrm{C}$ temperature and $1 \mathrm{~kW} / \mathrm{m}^{2}$ solar irradiation), $K_{1}$ is the temperature coefficient, $T_{r e f}$ is the reference temperature $\left(25^{\circ} \mathrm{C}\right), \lambda$ is the solar irradiation, $N_{S}$ is the number of the series cells, and $N_{P}$ is the number of parallel cells.

Then the photovoltaic current of the array can be expressed as:

$$
\begin{aligned}
& I_{P V}=N_{P} \times I \\
& -N_{P} \times I_{S}\left(\exp \left(\frac{q\left(V_{P V}+\frac{N_{S}}{N_{P}} \times I_{P V} \times R_{S}\right)}{N_{S} \times \alpha \times K \times T}\right)-1\right) \\
& -\frac{V_{P V}+\frac{N_{S}}{N_{P}} \times I_{P V} \times R_{S}}{\frac{N_{S}}{N_{P}} \times R_{S h}}
\end{aligned}
$$

For uniform irradiation, the (I-V) and (P-V) curves, which represent the characteristics of the PV array, have only one peak of maximum power point (MPP) that represents the maximum power generated from the PV array as shown in Fig. 3. It is worth mentioning that the maximum value of the current drawn from the PV array represents the short circuit current $\left(I_{S C}\right)$ achieved when the voltage across PV array terminals is zero, as shown in Fig. 3 (b). On the other hand, the maximum value of the voltage across the PV array terminals represents the opencircuit voltage $\left(V_{O C}\right)$ achieved when the current of the $\mathrm{PV}$ array is zero. There is no operation point at $I_{S C}$ and $V_{O C}$ and the maximum power generation of the $\mathrm{PV}$ array is achieved at a value lower than the vales 


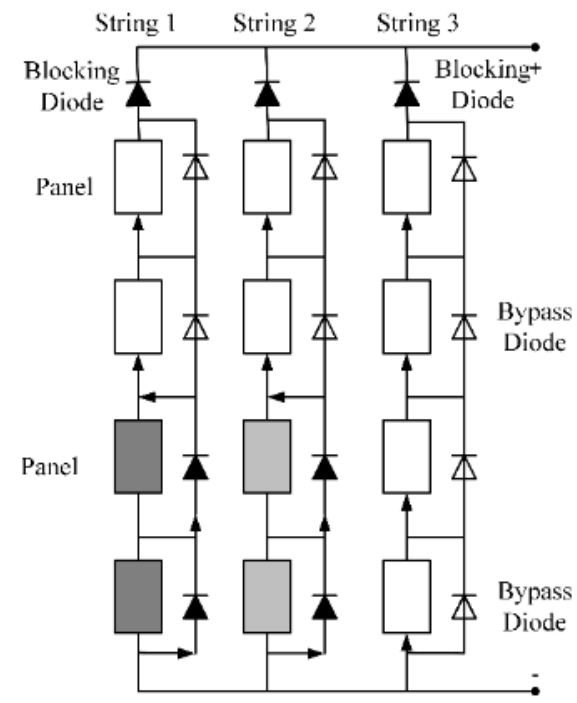

Figure. 1 Partial shading of a solar array

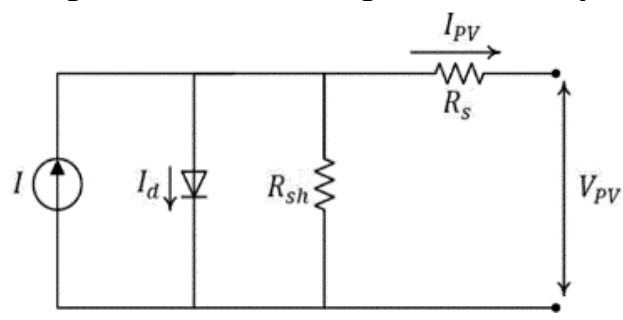

Figure. 2 Photovoltaic cell model

of $I_{S C}$ and $V_{O C}$, also named the voltage and current at MPP ( $V_{M P P}$ and $I_{M P P}$ ). However, in the partial shading conditions (non-uniform irradiation), the (I$\mathrm{V})$ and $(\mathrm{P}-\mathrm{V})$ curves have multiple peaks of maximum power points, as shown in Fig.4. Only one of these points is the global maximum power point (GMPP), and others represent the local maximum power point (LMPP), as shown in Fig. 4 (a) [33].

Indeed, the partial shading condition is caused by the shadow of a nearby tree or building and passing clouds. This condition causes a hot spot problem at the shaded PV panels that are connected in series with no-shaded PV panels. This problem may lead to thermal breakdown of shaded PV panels. As can be seen in Fig. 1, a bypass diode is connected in parallel with every PV panel in the string to prevent the hot spot problem. Blocking diode shown in Fig. 1 is also connected in series with every string to avoid the current passing from other strings connected in parallel [34].

\section{Conventional PSO algorithm}

The conventional PSO algorithm is based on the social behavior of flocks of birds or fishes. In order to explore the best food location, the PSO method employs a swarm of particles that floats at a multidimensional search space. Each particle represents a possible solution affected by the experiences of its

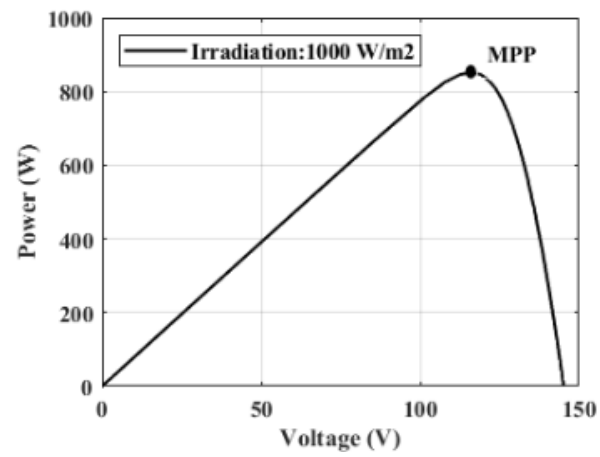

(a)

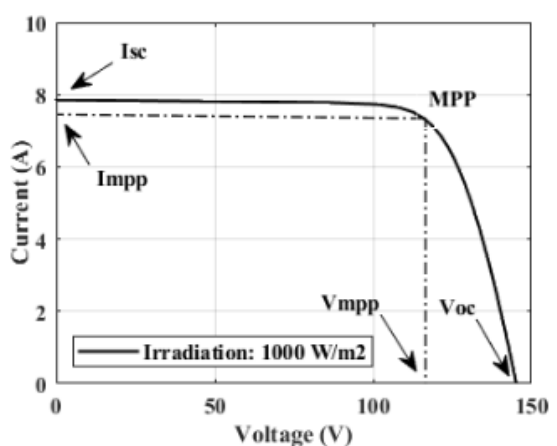

(b)

Figure. 3: (a) Power-voltage curve and (b) current-voltage curve for PV array characteristics at uniform irradiation in (a) and (b), respectively

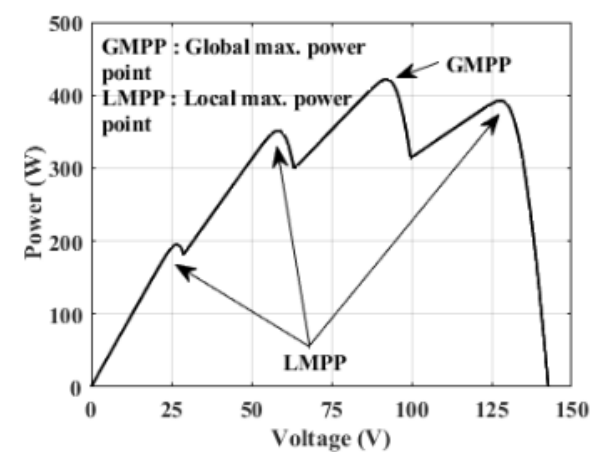

(a)

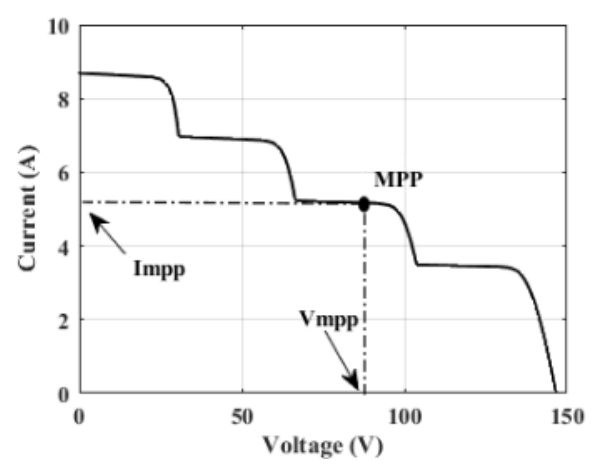

(b)

Figure. 4: (a) Power-voltage curve and (b) current-voltage curve for PV array characteristics at non-uniform irradiation in (a) and (b), respectively 
neighbors and itself. The final solution of particles can be expressed by the velocity and the position presented in (7) and (8), respectively [35].

$$
\begin{gathered}
V_{X_{i}+1}=\left(W \times V_{X_{i}}\right)+\left(C_{1} \times \operatorname{rand}(1) \times\left(P_{\text {best }}-\right.\right. \\
\left.\left.X_{i}\right)\right)+\left(C_{2} \times \operatorname{rand}(1) \times\left(G_{\text {best }}-X_{i}\right)\right) \\
X_{i+1}=X_{i}+V_{X i+1}
\end{gathered}
$$

where $V_{X_{i}}$ represents the current particle velocity, rand(1) is random numbers $(0-1), W$ is inertia weight, $C_{1}$ is the global acceleration coefficient, $C_{2}$ is personal acceleration coefficient, $G_{\text {best }}$ is best position of the particles in the entire population, $P_{\text {best }}$ is the personal best position of a particle, and $X_{i}$ is the current position of a particle.

The behavior of the conventional PSO algorithm mainly depends on the values of the coefficients $W$, $C_{1}$ and $C_{2}$ presented in the velocity equation. The effect of inertia weight $W$ on particle movement is like the fluidity of the medium, and it is responsible for ensuring the balance between the global and local exploration capabilities of the algorithm. The large value of $W$ facilitates comprehensive exploration and identifies new areas in the scope of the search while the small value of $W$ facilitates local exploration to improve the current search area. The effect of $C_{1}$ and $C_{2}$ coefficients represent the particle attraction force toward the optimal position, and the choice of their values is different from one application to another. The random numbers presented in the velocity equation improve the search process, by impacting the movement of the particles in zigzag directions to cover the entire search range [36].

\section{Proposed MPPT method based on EPSO algorithm}

The PSO algorithm has an excellent response to many applications. As mentioned before, the search accuracy of the PSO algorithm depends on coefficient values of the velocity equation (i.e., $\mathrm{C}_{1}, \mathrm{C}_{2}$ and $\mathrm{W}$ ), which specify the particle behavior in search space. Although the random numbers presented in the velocity equation are responsible for keeping the stochastic movement of the particles within iterations to reach the better solution. The two terms $\mathrm{C}_{1} \times\left(\mathrm{P}_{\text {best }}-\mathrm{X}_{\mathrm{i}}\right)$ and $\mathrm{C}_{2} \times\left(\mathrm{G}_{\text {best }}-\mathrm{X}_{\mathrm{i}}\right)$ multiplied by random numbers in (7) might cause a significant change in the particle velocity that causes the particles to diverge from the best solution or cause a long computational time of the search for the online MPPT application [37].
In this paper, an Enhanced Particle Swarm Optimization (EPSO) algorithm is proposed to track the maximum power point in the PV system under the partial shading condition. The proposed algorithm is based on setting the values of acceleration coefficients $\left(C_{1} \& C_{2}\right)$ to unity and removing the random numbers presented in the velocity equation of the conventional PSO algorithm to decrease the zigzag or the winding of the particles and subsequently reduce the searching time, the oscillation of the output power, and the power losses. Therefore, the proposed velocity equation shown in Eq. (9) will only depend on the linear decreasing of the inertia weight $(W)$ within iterations.

$$
V_{X_{i}+1}=V_{X_{i}} \times W+\left(G_{\text {best }}+P_{\text {best }}\right)-\left(2 \times X_{i}\right)
$$

where $G_{\text {best }}, P_{\text {best }}$ and $X_{i}$ for MPPT application represent the best duty cycle of the particles in the entire population, the personal particle best of duty cycle, and the current duty cycle, respectively. The proposed inertia weight is given in Eq. (10):

$$
W=\left(\left(W_{M A X}-W_{M I N}\right) \times \frac{N-J}{N}\right)+W_{M I N}
$$

where $W_{M A X}$ and $W_{M I N}$ represents the maximum and minimum value of inertia weight, respectively. $N$ represents the maximum number of iterations, and $J$ represents the current iteration number.

The value of $W$ mentioned in (10) is decreased within iterations. Initially, a large value of $W$ is produced to achieve large particles' velocity and subsequently increase the convergence time to reach the GMPP. On the other hand, when the particles reach near the GMPP after some iterations, a small value of $W$ is required to reduce the step size presented by velocity towards the GMPP. The values of $W_{M A X}$ and $W_{M I N}$ that achieve fast and reliable convergence of particles depend on the application. In this paper, the values of $W_{M A X}$ and $W_{M I N}$ are chosen to be 0.45 and 0.2 , respectively.

The proposed inertia weight equation is also proposed in [24], [38]. However, the methodologies of these methods were different from the proposed ones. In [24], [38], the random numbers and acceleration coefficients were kept in the velocity equation causing deterioration to the behavior of the methods through the high oscillation in the PV generated power and the slow tracking of MPP. In addition, the method proposed in [24] is considered as a very expensive and difficult solution to the problem of tracking the MPP due to the requirements of the method to a set of sensors to measure the PV 
system temperature and the amount of radiation falling on each PV panel.

In this paper, the proposed algorithm is reinitialized when the loads and/or the atmospheric conditions are changed to ensure that the proposed algorithm is always capable of tracking the GMPP under different conditions. The reinitialization of the proposed algorithm can be satisfied by using (11).

$$
\left|\frac{P_{P V_{\text {new }}}-P_{P V_{\text {old }}}}{P_{P V_{\text {old }}}}\right| \geq \Delta P
$$

where $\Delta P$ is the minimum relative error utilized to reinitialize the algorithm, $P_{P V \text { new }}$ and $P_{P V}$ old represent the power obtained in the current and previous iterations, respectively.

The main procedure of the proposed MPPT method is shown in Fig. 5.

\section{Overview of MPPT method based on VPSO-LF algorithm}

To verify the superiority of the proposed method, the well-known meta-heuristic method, which is based on velocity PSO- Lévy Flight Algorithm, is used for comparison. The VPSO-LF is described briefly in this section.

The VPSO-LF presented in [31] is based on the Lévy Flight concept to control the velocity equation of the conventional PSO algorithm. Lévy flights (or Lévy motion) is a class of non-Gaussian random processes whose random walks are drawn from Lévy stable distribution $[39,40]$.

In this method, the Levy Flight concept is employed to control the PSO velocity equation when the random number is less than 0.25 . Thus, the velocity of particles is updated using (12) and (13). On the other hand, when the random number is greater than or equal to 0.25 , the conventional velocity equation is utilized as in (7).

$$
\begin{gathered}
V_{X_{i}+1}=\left(W \times \operatorname{Lévy} \text { walk }\left(x_{i}^{r}\right)\right)+ \\
\left(C_{1} \times \operatorname{rand}(1) \times\left(P_{\text {best }}-X_{i}\right)\right)+ \\
\left(C_{2} \times \operatorname{rand}(1) \times\left(G_{\text {best }}-X_{i}\right)\right)
\end{gathered}
$$

$\operatorname{Lévy} \operatorname{walk}\left(x_{i}^{r}\right)=\alpha \oplus \operatorname{Levy}(\lambda)$

$$
\begin{aligned}
& =\alpha_{o}\left(p_{\text {best }}-x_{i}\right) \oplus \operatorname{Levy}(\lambda) \\
& \cong K\left(\frac{u}{(|v|)^{1 / \beta}}\right)\left(p_{\text {best }}-x_{i}\right)
\end{aligned}
$$

where $\alpha$ is a parameter within the range of $[-1,1], \alpha_{0}$ is the initial step change, $\beta$ is the stability index $\in(0$, 2 ), $u$ and $v$ are obtained from a normal distribution, and $K$ is a multiplying factor.
Although this method increases the search efficiency, the combination between the Lévy Flight concept and the random parameters in the velocity equation may cause the winding of the particles during the online tracking process.

\section{Results and discussion}

In order to verify the behavior and accuracy of the proposed method, a PV system is implemented using the MATLAB/Simulink environment and tested under different partial shading patterns and different load values.

The tested PV system shown in Fig. 6 includes a string formed by four panels connected in series, a DC-DC boost converter, and a load. The PV string has a maximum power of $852.6 \mathrm{~W}$, maximum power point current of $7.35 \mathrm{~A}$, and maximum power point voltage of $116 \mathrm{~V}$. The $\mathrm{DC} / \mathrm{DC}$ converter components values are: $\mathrm{C} 1=\mathrm{C} 2=50 \mu \mathrm{F}, \mathrm{L}=1.5 \mathrm{mH}$ and the switching frequency is $20 \mathrm{kHz}$. To obtain the maximum power point, the tracker based on the proposed method is considered.

The specifications of the PV panel are listed in Table 1. The considered string is tested according to six different levels of irradiance profile listed in Table 2 and two different load values of $50 \Omega$ and $100 \Omega$. The aim of using different irradiation patterns is to examine the reliability and robustness of the proposed algorithm when the global maximum power point is moving along the $\mathrm{P}-\mathrm{V}$ curve search space.

Fig. 7 (a) presents the P-V characteristic when a uniform irradiance of $1 \mathrm{KW} / \mathrm{m}^{2}$ is applied on all panels. As shown in this figure, there is only one peak power point of $852.6 \mathrm{~W}$ at $116 \mathrm{~V}$ and 7.35A. Fig. 7 (b) shows the string output power and duty cycle obtained for the same irradiance pattern case with 50 $\Omega$ load initially applied. Then it is changed to $100 \Omega$ at $\mathrm{t}=0.5 \mathrm{~s}$. From the results presented in this figure the values of the tracking time obtained for the two load cases (i.e., $50 \Omega$ and $100 \Omega$ ) are $0.186 \mathrm{~s}$, and $0.206 \mathrm{~s}$, respectively.

The output MPP powers obtained are $852.4 \mathrm{~W}$ for $50 \Omega$ load and $852.2 \mathrm{~W}$ for $100 \Omega$ load, which are very closed to the optimum MPP demonstrating the high tracking efficiency of $99.97 \%$ and $99.95 \%$ for the two load cases, respectively.

Besides the low tracking time and the high tracking efficiency obtained using the proposed method, the oscillation in the output power is very low, which verifies the ability of the proposed method to decrease the oscillation and improve the quality of the output power. 


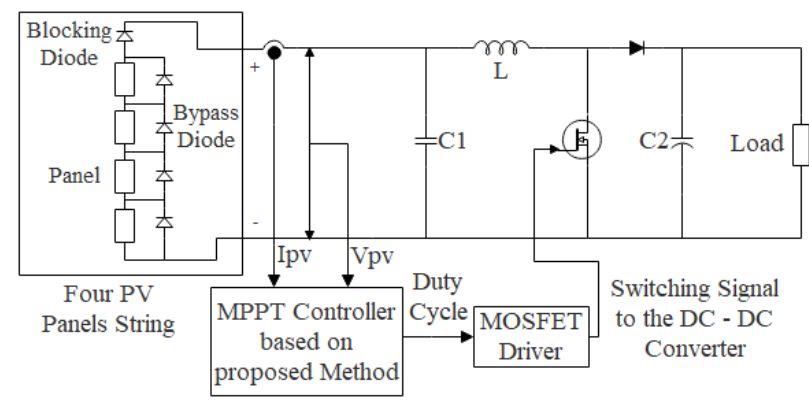

Figure. 6 Configuration of the tested PV system

Table 1. PV panel specifications

\begin{tabular}{|c|c|c|c|c|}
\hline$P_{\text {Max. }}$ & $V_{O C}$ & $V_{M P P}$ & $I_{S C}$ & $I_{M P P}$ \\
\hline 213.15 & 36.3 & 29 & 7.84 & 7.35 \\
\hline
\end{tabular}

Table 2. Irradiance patterns

\begin{tabular}{|l|ll|}
\hline $\begin{array}{l}\text { Pattern } \\
\text { no. }\end{array}$ & \multicolumn{3}{|c|}{ Irradiance $\left(\mathbf{W} / \mathbf{m}^{\mathbf{2}}\right)$} \\
\hline Pattern 1 & {$\left[\begin{array}{llll}1000 & 1000 & 1000 & 1000\end{array}\right]$} \\
\hline Pattern 2 & {$\left[\begin{array}{llll}1000 & 1000 & 1000 & 400\end{array}\right]$} \\
\hline Pattern 3 & {$\left[\begin{array}{llll}1000 & 1000 & 800 & 400\end{array}\right]$} \\
\hline Pattern 4 & {$\left[\begin{array}{llll}1000 & 800 & 600 & 400\end{array}\right]$} \\
\hline Pattern 5 & {$\left[\begin{array}{llll}1000 & 400 & 400 & 400\end{array}\right]$} \\
\hline Pattern 6 & {$\left[\begin{array}{llll}1000 & 900 & 500 & 300\end{array}\right]$} \\
\hline
\end{tabular}

Moreover, a change in the load value occurred at a time of $0.5 \mathrm{~s}$. The proposed method sensed this change in the PV load and reinitialized the algorithm at a $0.529 \mathrm{~s}$ with a time delay of only $29 \mathrm{~ms}$. These results verified the ability of the proposed method to track the GMPP under the variation of the system operating conditions.

Fig. 8 shows the obtained results when the proposed method for the partial shading irradiance case (i.e., pattern 2) is applied with loads of $50 \Omega$ and $100 \Omega$. It is noticed from the P-V characteristic presented in Fig. 8 (a) that there are two peaks in the P-V curve. The first one is the GMPP and the second peak is LMPP. The global power generated is $633.5 \mathrm{~W}$ at voltage 86.26V and current of 7.344A. Fig. 8 (b) shows the results of the string output power and duty cycle. From these results, the oscillation in the output power is very low, and the tracking time obtained is $0.146 \mathrm{~s}$ for resistance $50 \Omega$ and 0.185 s for resistance $100 \Omega$. while the output powers/tracking efficiencies for the two loads cases are $633.3 \mathrm{~W} / 99.96 \%$ and $633.4 \mathrm{~W} /$ $99.98 \%$, respectively. These results demonstrate the accuracy and effectiveness of the proposed method to track the MPP in the case of non- uniform irradiance.

The same test strategy is applied for pattern 3 , pattern 4 , pattern 5 , and pattern 6 , and the obtained

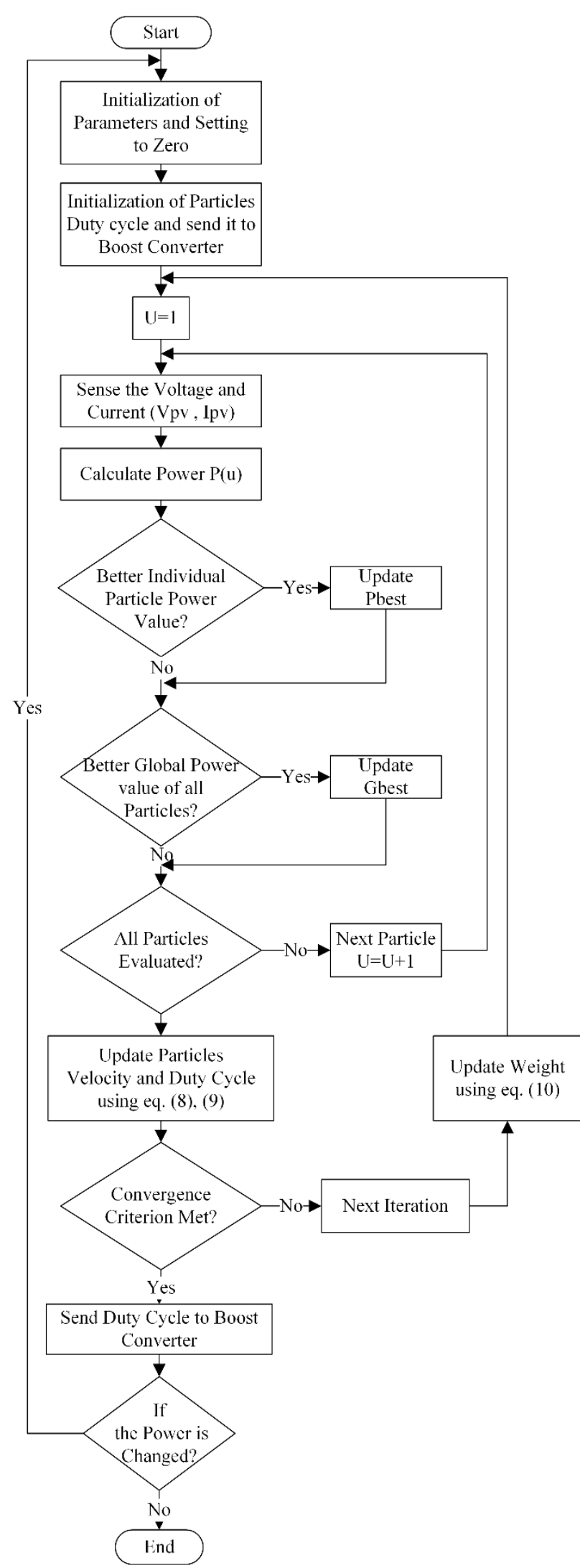

Figure. 5 Flowchart of the proposed MPPT method

results are shown in Figs. 9, 10, 11, and 12, respectively. The results obtained for all patterns are summarized in Table 3 . The obtained results in Table 


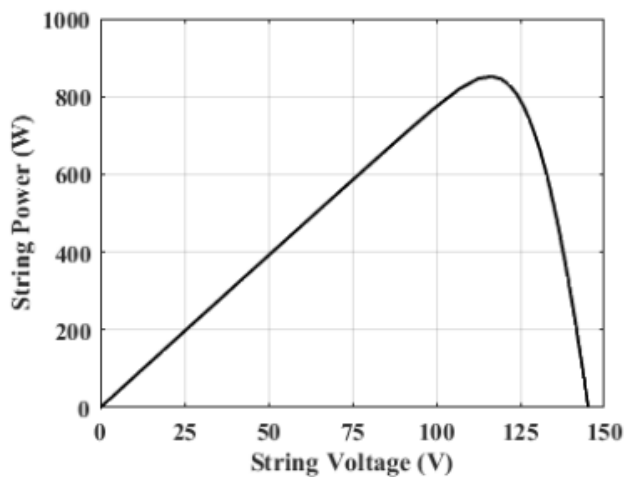

(a)
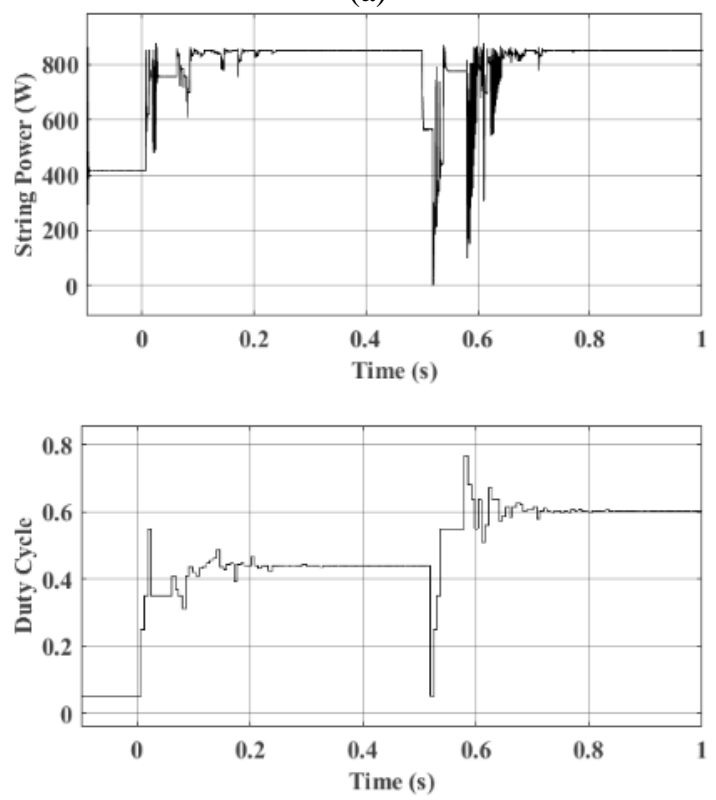

(b)

Figure. 7: (a) P-V curve and (b) the string power and duty cycle using the proposed method for the pattern (1)

3 show the effectiveness and efficiency of the proposed method in tracking the global maximum power point under different patterns and loads. From Table 3, it is noticed that the tracking time range is $(0.146 \mathrm{~s}-0.273 \mathrm{~s})$; the range of a number of iterations is (6-11), while the range of the tracking efficiency is $(99.91 \%$ $99.98 \%$ ). Finally, in order to demonstrate the effectiveness of the proposed method at different system configurations, the proposed method is applied to a string of 10 panels at loads of $55 \Omega$ and $100 \Omega$ at shading pattern of [ $\begin{array}{lllll}1.0 & 0.9 & 0.8 & 0.7\end{array}$ $0.60 .50 .40 .30 .20 .1] \mathrm{KW} / \mathrm{m}^{2}$.

Fig. 13 (a) represents the P-V characteristic curve applied when partial shading occurs. As shown in this figure, there are ten peak power points; one of them is GMPP. The global power is $721.6 \mathrm{~W}$ at voltage of 187.2V and current of 3.855A. Fig. 13 (b) shows the string power and duty cycle obtained using the

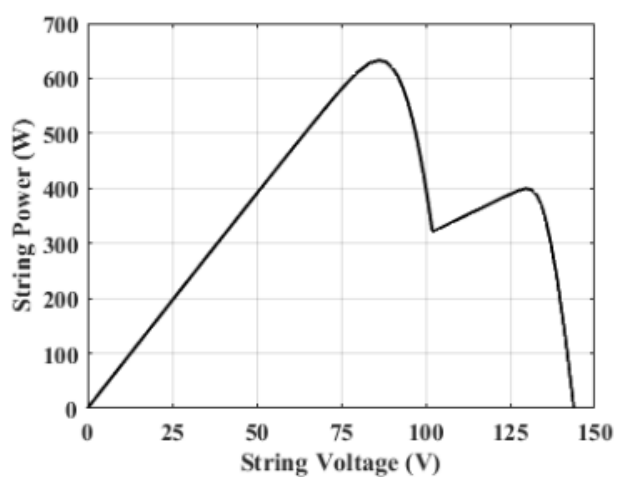

(a)
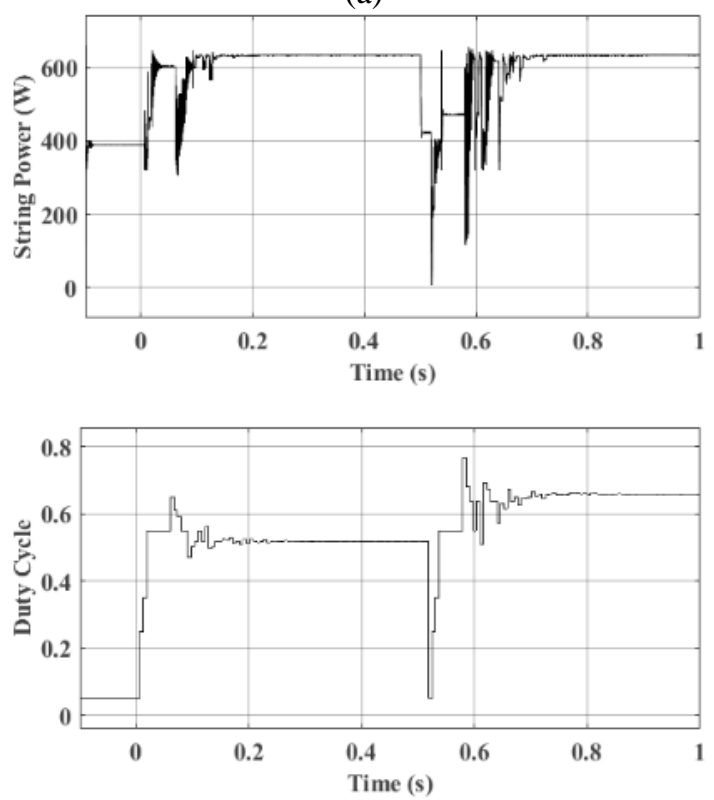

(b)

Figure. 8: (a) P-V curve and (b) the string power and duty cycle using the proposed method for the pattern (2)

proposed method. From this figure, it is noticed that the string powers generated are $721.4 \mathrm{~W}$ and $721.5 \mathrm{~W}$, the values of the tracking time are $0.205 \mathrm{~s}$ and $0.222 \mathrm{~s}$, and the tracking efficiencies are $99.97 \%$ and $99.98 \%$ for two loads $(55 \Omega$ and $100 \Omega)$, respectively.

In order to demonstrate the superiority of the proposed method, the obtained results are compared with a well-known method, which is based on VPSOLF [31] under the same conditions.

The proposed method is compared with the VPSOLF method at $10 \mathrm{KHz}$ switching frequency, three searching particles, and 8 shading patterns of irradiation with the same temperature and load conditions.

Tables 4, 5, and 6 show the comparison results between the proposed method and the VPSO-LF method presented in [31] for the case of three, four, and six series PV modules configurations, respectively. The comparison between the two methods is carried out in terms of tracked PV power and tracking efficiency and time. 


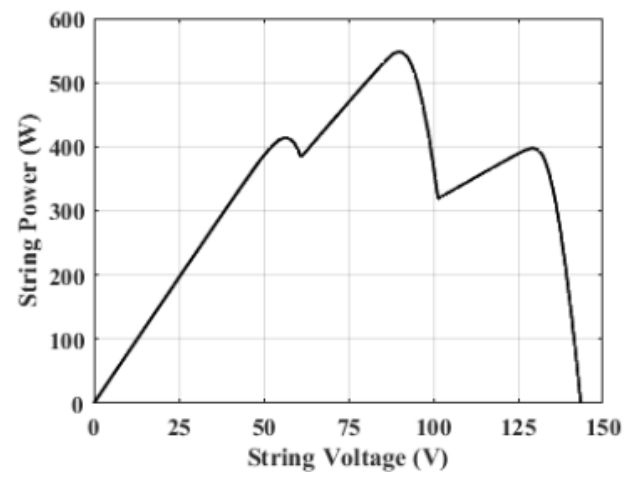

(a)
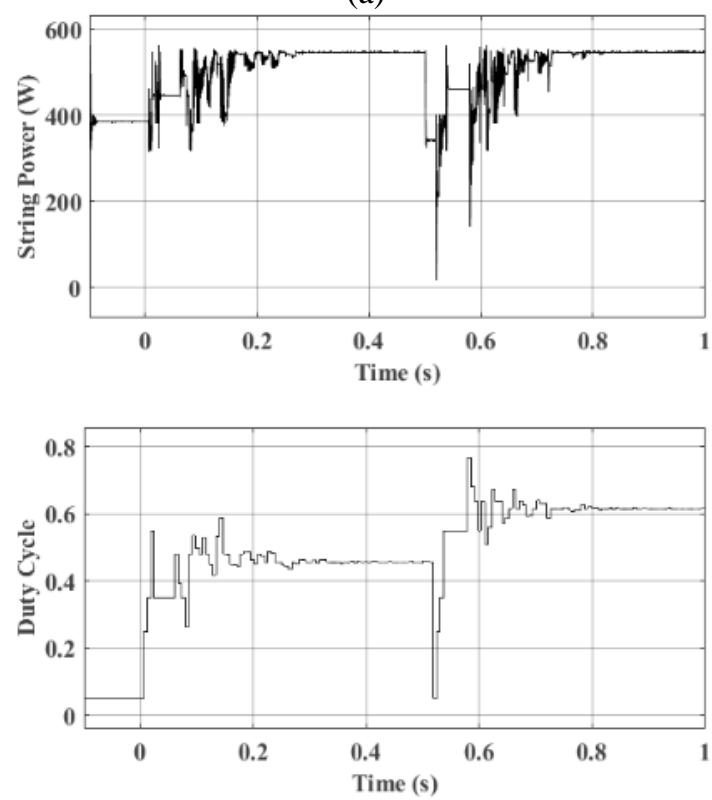

(b)

Figure. 9: (a) P-V curve and (b) the string power and duty cycle using the proposed method for the pattern (3)

It can be concluded from these tables that the tracking time of the VPSO-LF method is about $(0.23 \mathrm{~s}-0.87 \mathrm{~s})$, while the tracking time of the proposed method is about $(0.133 \mathrm{~s}-0.224 \mathrm{~s})$. In addition, the lowest tracking efficiency of the VPSO-LF method is 99.07\%. On the other hand, the lowest tracking efficiency of the proposed method is $99.98 \%$.

For the eight irradiation patterns presented in Tables 4, 5, and 6 , the values of the tracked power obtained using the proposed method are higher than those values obtained using the VPSO-LF method. As an example, at shading pattern [0.8-0.6-0.5] $\mathrm{KW} / \mathrm{m} 2$ in Table 4 , the tracked power obtained using the proposed method is $(97.6 \mathrm{~W})$ while the tracked power of the VPSO-LF method is $(94.58 \mathrm{~W})$.

Although the VPSO-LF method increases the search efficiency that is required for off-line complex optimization problems, the combination between the Lévy Flight concept and the random parameters in the velocity equation causes winding of the particles during the online tracking process. Consequently, the

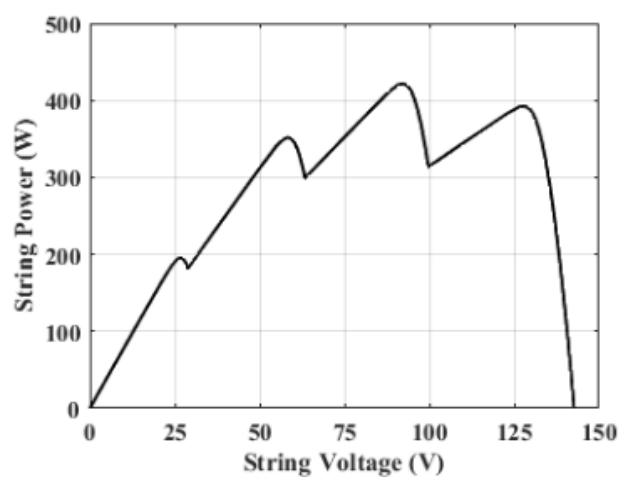

(a)
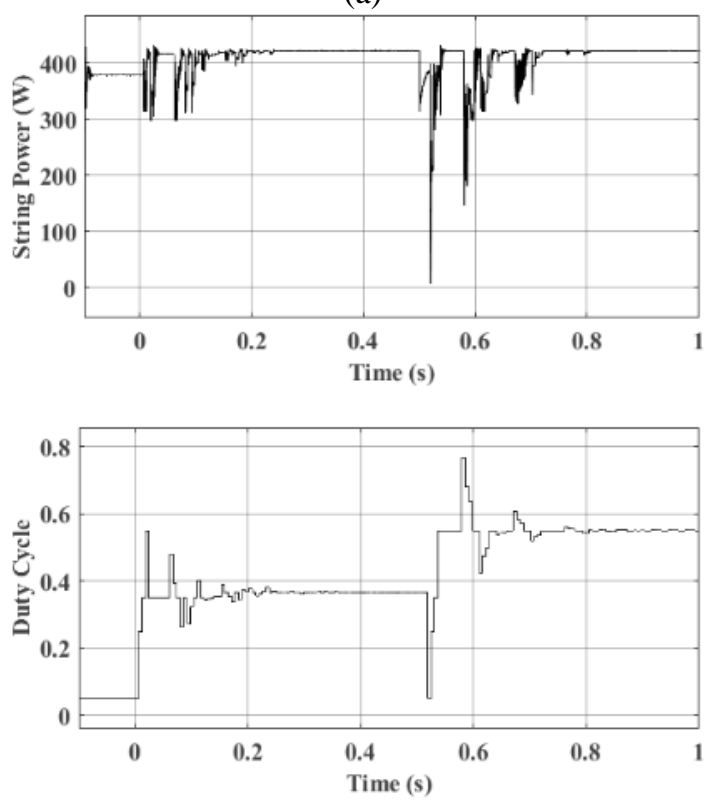

(b)

Figure. 10: (a) P-V curve and (b) the string power and duty cycle using the proposed method for the pattern (4)

winding performance of the particles represents the reason behind the long searching time and the high oscillation in the output power that reduces the root mean square value of the output power and decreases the tracking efficiency.

On the other hand, the proposed velocity equation developed in this paper only depends on the linear decreasing of the inertia weight within iterations with removing the random numbers presented in the velocity equation of the conventional PSO algorithm to reduce the zigzag or the winding of the particles. The simulation results and comparison study verified the effectiveness and superiority of the proposed method.

\section{Conclusion}

This paper presents a modification on the classical PSO algorithm to find the global maximum power point of a solar system under partial shading conditions. The obtained results reveal that the 


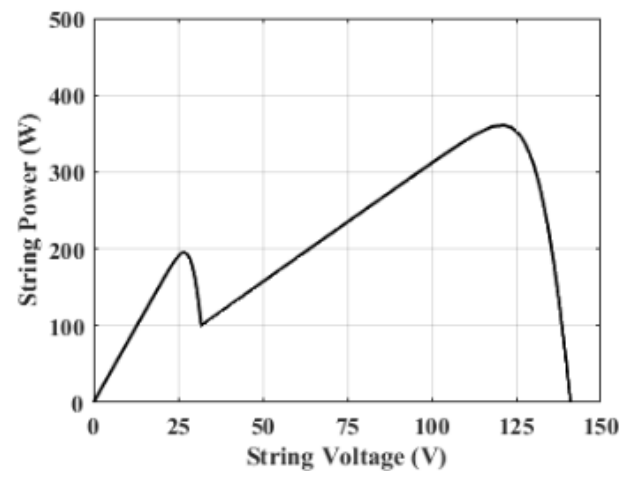

(a)
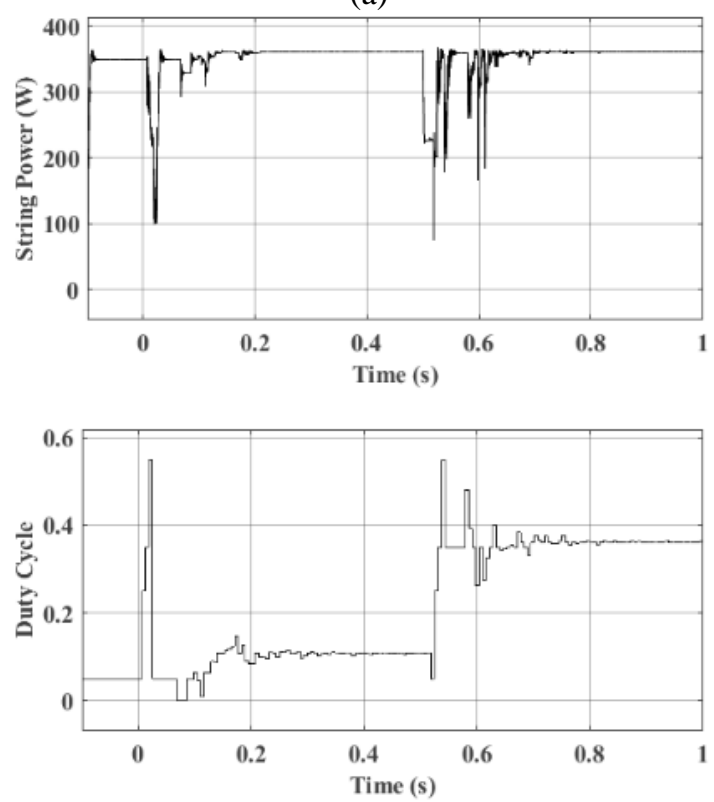

(b)

Figure. 11: (a) P-V curve and (b) the string power and duty cycle using the proposed method for the pattern (5)

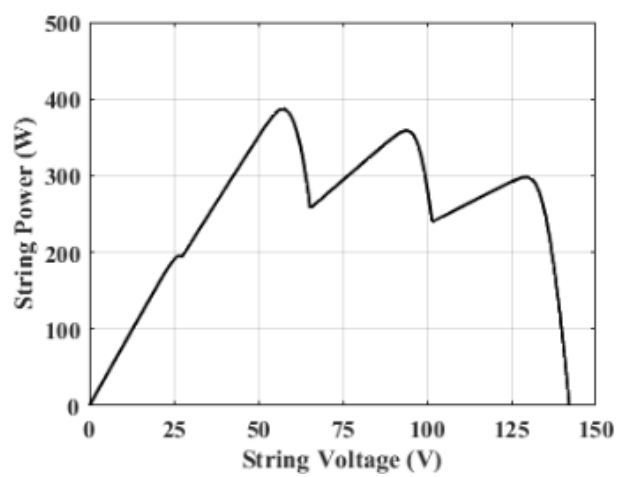

(a)
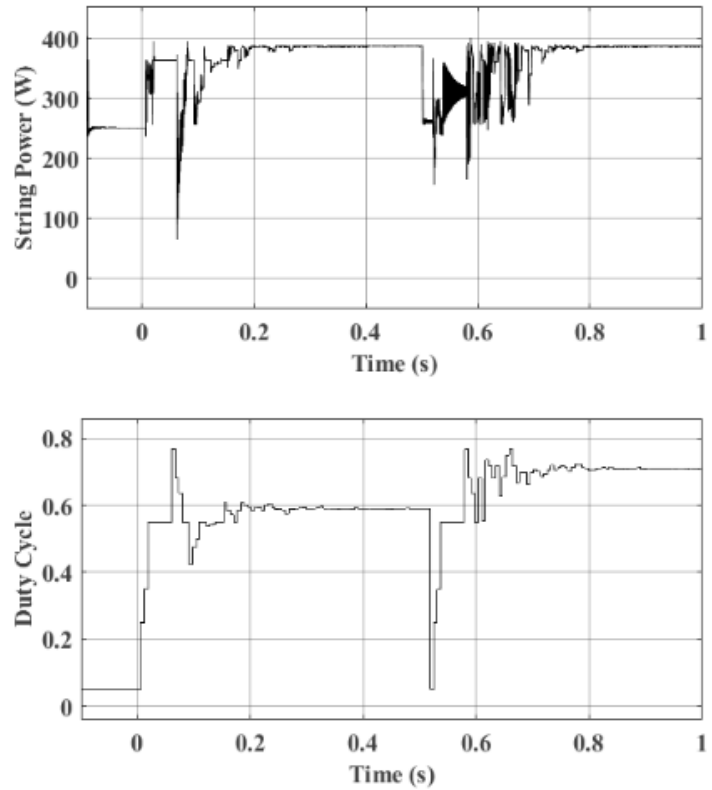

(b)

Figure. 12: (a) P-V curve and (b) the string power and duty cycle using the proposed method for the pattern (6)

Table 3. The results obtained using the proposed method

\begin{tabular}{|c|c|c|c|c|c|c|c|c|c|}
\hline \multirow[b]{2}{*}{$\begin{array}{l}\text { Pattern } \\
\text { at } 25^{\circ} \mathrm{C}\end{array}$} & \multirow{2}{*}{$\begin{array}{c}\text { Load } \\
\text { Value } \\
(\Omega)\end{array}$} & \multirow[b]{2}{*}{$\begin{array}{c}\text { Voltage } \\
\text { (V) }\end{array}$} & \multirow[b]{2}{*}{$\begin{array}{l}\text { Current } \\
\text { (A) }\end{array}$} & \multirow[b]{2}{*}{$\begin{array}{l}\text { Duty } \\
\text { Cycle }\end{array}$} & \multicolumn{2}{|c|}{ Tracking Speed } & \multirow{2}{*}{$\begin{array}{l}\text { Tracked } \\
\text { Power } \\
\text { (W) }\end{array}$} & \multirow{2}{*}{$\begin{array}{c}\text { Global } \\
\text { power } \\
(\mathrm{W})\end{array}$} & \multirow{2}{*}{$\begin{array}{c}\text { Tracking } \\
\text { Efficiency } \\
(\%)\end{array}$} \\
\hline & & & & & $\begin{array}{c}\text { Time } \\
\text { (s) }\end{array}$ & $\begin{array}{c}\text { No. of } \\
\text { iterations }\end{array}$ & & & \\
\hline \multirow[t]{2}{*}{ Pattern 1} & 50 & 116 & 7.349 & 0.4397 & 0.186 & 7 & 852.4 & \multirow{2}{*}{852.6} & 99.97 \\
\hline & 100 & 116 & 7.346 & 0.603 & 0.206 & 8 & 852.2 & & 99.95 \\
\hline \multirow[t]{2}{*}{ Pattern 2} & 50 & 86.19 & 7.348 & 0.518 & 0.146 & 6 & 633.3 & \multirow{2}{*}{633.5} & 99.96 \\
\hline & 100 & 86.27 & 7.342 & 0.658 & 0.185 & 7 & 633.4 & & 99.98 \\
\hline \multirow[t]{2}{*}{ Pattern 3} & 50 & 90.32 & 6.074 & 0.4574 & 0.273 & 11 & 548.6 & \multirow{2}{*}{548.8} & 99.96 \\
\hline & 100 & 90.1 & 6.088 & 0.6169 & 0.211 & 8 & 548.5 & & 99.94 \\
\hline \multirow[t]{2}{*}{ Pattern 4} & 50 & 92.36 & 4.568 & 0.3665 & 0.21 & 8 & 421.9 & \multirow{2}{*}{422} & 99.97 \\
\hline & 100 & 92.69 & 4.552 & 0.551 & 0.206 & 8 & 421.92 & & 99.98 \\
\hline \multirow[t]{2}{*}{ Pattern 5} & 50 & 120.3 & 3.002 & 0.1064 & 0.215 & 9 & 361.1 & \multirow{2}{*}{361.4} & 99.91 \\
\hline & 100 & 121.1 & 2.984 & 0.3639 & 0.195 & 8 & 361.3 & & 99.97 \\
\hline \multirow[t]{2}{*}{ Pattern 6} & 50 & 57.45 & 6.741 & 0.5899 & 0.198 & 8 & 387.2 & \multirow{2}{*}{387.3} & 99.97 \\
\hline & 100 & 57.07 & 6.783 & 0.7199 & 0.273 & 11 & 387.1 & & 99.94 \\
\hline
\end{tabular}

proposed algorithm (EPSO) is effectively capable of minimizing the tracking time and the number of iterations for different irradiances and load conditions (i.e., the highest number of iterations is 11 iterations and the highest tracking time is $0.273 \mathrm{~s}$ ). Also, the obtained results prove that the proposed method is more stable in attaining the real GMPP and decreases the oscillation of the duty cycle compared to other 


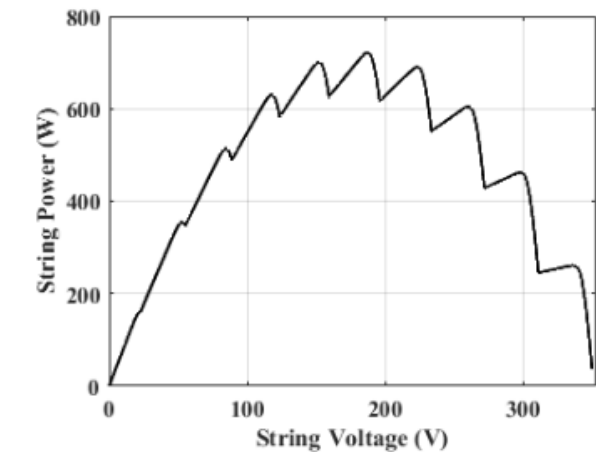

(a)
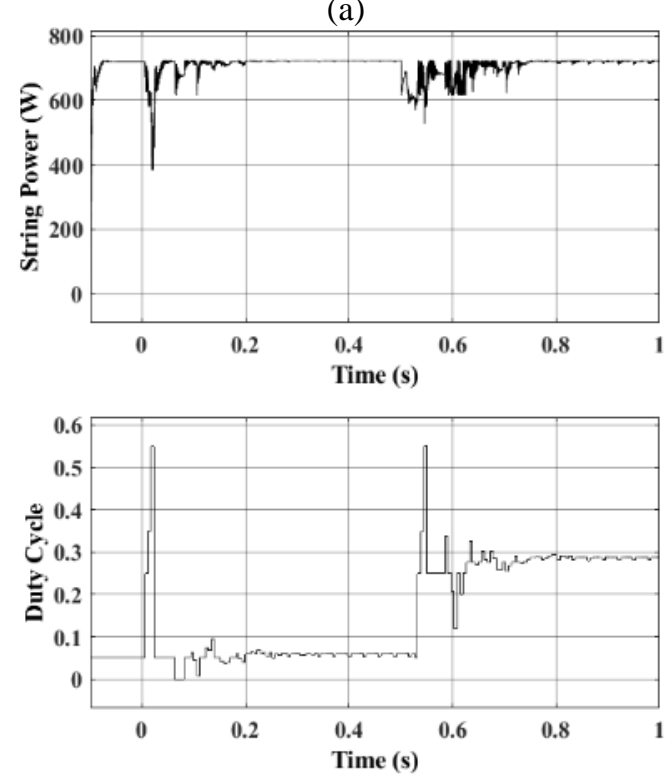

(b)

Figure. 13: (a) P-V curve and (b) the string power and duty cycle using the proposed method for ten panels string

Table 4. The simulation results for the case of three series modules configuration and three searching particles

\begin{tabular}{|c|c|c|c|c|}
\hline $\begin{array}{l}\text { Shading } \\
\text { Pattern }\end{array}$ & Method & $\begin{array}{c}\text { Tracked } \\
\text { Power } \\
(W) \\
\end{array}$ & $\begin{array}{l}\text { Tracking } \\
\text { Time } \\
\text { (s) }\end{array}$ & $\begin{array}{c}\text { Tracking } \\
\text { Efficiency } \\
(\%)\end{array}$ \\
\hline \multirow{2}{*}{$\begin{array}{c}{[1.0-0.4-} \\
0.2] \\
\mathrm{KW} / \mathrm{m}^{2}\end{array}$} & $\begin{array}{c}\text { VPSO- } \\
\text { LF }\end{array}$ & 53.39 & 0.3 & 99.85 \\
\hline & Proposed & 54.12 & 0.149 & 99.98 \\
\hline \multirow{2}{*}{$\begin{array}{c}{[1.0-0.6-} \\
0.3] \\
\mathrm{KW} / \mathrm{m}^{2}\end{array}$} & $\begin{array}{c}\text { VPSO- } \\
\text { LF }\end{array}$ & 73.95 & 0.71 & 99.70 \\
\hline & Proposed & 75.8 & 0.196 & 99.99 \\
\hline \multirow{2}{*}{$\begin{array}{c}{[0.8-0.6-} \\
0.5] \\
\mathrm{KW} / \mathrm{m}^{2}\end{array}$} & $\begin{array}{c}\text { VPSO- } \\
\text { LF }\end{array}$ & 94.58 & 0.75 & 99.97 \\
\hline & Proposed & 97.6 & 0.133 & 99.98 \\
\hline \multirow{2}{*}{$\begin{array}{c}{[1.0-0.7-} \\
0.6] \\
\mathrm{KW} / \mathrm{m}^{2}\end{array}$} & $\begin{array}{c}\text { VPSO- } \\
\text { LF }\end{array}$ & 114.7 & 0.23 & 99.99 \\
\hline & Proposed & 117.4 & 0.162 & 99.99 \\
\hline
\end{tabular}

Table 5. The simulation results for the case of four series modules configuration and three searching particles

\begin{tabular}{|c|c|c|c|c|}
\hline $\begin{array}{c}\text { Shading } \\
\text { Pattern }\end{array}$ & Method & $\begin{array}{c}\text { Tracked } \\
\text { Power } \\
(\mathbf{W})\end{array}$ & $\begin{array}{c}\text { Tracking } \\
\text { Time } \\
\text { (s) }\end{array}$ & $\begin{array}{c}\text { Tracking } \\
\text { Efficiency } \\
(\%)\end{array}$ \\
\hline $\begin{array}{c}{[1.0-0.9-} \\
0.8-0.4] \\
\text { KW/m }\end{array}$ & $\begin{array}{c}\text { VPSO- } \\
\text { LF }\end{array}$ & 148.59 & 0.75 & 99.50 \\
\cline { 2 - 5 } & Proposed & 150.8 & 0.182 & 99.98 \\
\hline$[1.0-0.9-$ & $\begin{array}{c}\text { VPSO- } \\
\text { LF }\end{array}$ & 159.44 & 0.23 & 99.07 \\
\cline { 2 - 5 } KW/m² & Proposed & 162.5 & 0.183 & 99.99 \\
\hline
\end{tabular}

Table 6. The simulation results for the case of six series modules configuration and three searching particles

\begin{tabular}{|c|c|c|c|c|}
\hline $\begin{array}{c}\text { Shading } \\
\text { Pattern }\end{array}$ & Method & $\begin{array}{c}\text { Tracked } \\
\text { Power } \\
(\mathbf{W})\end{array}$ & $\begin{array}{c}\text { Tracking } \\
\text { Time } \\
(\mathbf{s})\end{array}$ & $\begin{array}{c}\text { Tracking } \\
\text { Efficiency } \\
(\%)\end{array}$ \\
\hline $\begin{array}{c}{[1.0-1.0-} \\
0.6-0.6- \\
0.3-0.3] \\
\text { KW/m }\end{array}$ & $\begin{array}{c}\text { VPSO- } \\
\text { LF }\end{array}$ & 149.48 & 0.87 & 99.86 \\
\cline { 2 - 5 }$\left[\begin{array}{c}\text { Proposed } \\
0.9-0.7-0- \\
0.4-0.3]\end{array}\right.$ & 151.8 & 0.161 & 99.99 \\
\cline { 2 - 5 } KW/m & LFSO- & 180.89 & 0.52 & 99.91 \\
\hline
\end{tabular}

method that reaches point closely to GMPP at some conditions of irradiance and loads.

\section{Conflicts of Interest}

The authors declare no conflict of interest.

\section{Author Contributions}

"Conceptualization, Anas Abduladheem Kamil and Shamam Alwash; methodology, Anas Abduladheem Kamil and Shamam Alwash; software, Anas Abduladheem Kamil and Shamam Alwash; validation, Anas Abduladheem Kamil and Shamam Alwash; formal analysis, Anas Abduladheem Kamil and Shamam Alwash; investigation, Anas Abduladheem Kamil and Shamam Alwash; resources, Anas Abduladheem Kamil and Shamam Alwash; data curation, Anas Abduladheem Kamil and Shamam Alwash; writing - original draft preparation, Anas Abduladheem Kamil and Shamam Alwash; writing-review and editing, Anas Abduladheem Kamil and Shamam Alwash; visualization, Anas Abduladheem Kamil and Shamam Alwash; supervision, Mahmoud Shaker Nasr; project administration, Mahmoud Shaker Nasr; funding acquisition, Mahmoud Shaker Nasr". 


\section{References}

[1] V. Kota and M. Bhukya, "A novel linear tangents based P\&O scheme for MPPT of a PV system", Renewable and Sustainable Energy Reviews, Vol. 71, No. March, pp. 257-267, 2017.

[2] R. Putri, S. Wibowo, and M. Rifa'i, "Maximum power point tracking for photovoltaic using incremental conductance method", Energy Procedia, Vol. 68, pp. 22-30, 2015.

[3] M. Shebani, T. Iqbal, and J. Quaicoe, "Comparing bisection numerical algorithm with fractional short circuit current and open circuit voltage methods for MPPT photovoltaic systems", In: Proc. of 2016 IEEE Electrical Power and Energy Conf., EPEC 2016.

[4] D. Baimel, R. Shkoury, L. Elbaz, S. Tapuchi, and N. Baimel, "Novel optimized method for maximum power point tracking in PV systems using Fractional Open Circuit Voltage technique", 2016 International Symposium on Power Electronics, Electrical Drives, Automation and Motion, SPEEDAM 2016, Vol. 2, pp. 889-894, 2016.

[5] J. Ram, T. Babu, and N. Rajasekar, "A comprehensive review on solar PV maximum power point tracking techniques", Renewable and Sustainable Energy Reviews, Vol. 67, pp. 826-847, 2017.

[6] S. Dash, S. Nema, R. Nema, and D. Verma, "A comprehensive assessment of maximum power point tracking techniques under uniform and non-uniform irradiance and its impact on photovoltaic systems: A review", Journal of Renewable and Sustainable Energy, Vol. 7, No. 6, 2015.

[7] K. Ishaque and Z. Salam, "A review of maximum power point tracking techniques of PV system for uniform insolation and partial shading condition", Renewable and Sustainable Energy Reviews, Vol. 19, pp. 475-488, 2013.

[8] L. Liu, X. Meng, and C. Liu, "A review of maximum power point tracking methods of PV power system at uniform and partial shading", Renewable and Sustainable Energy Reviews, Vol. 53, pp. 1500-1507, 2016.

[9] R. Alik and A. Jusoh, "Modified Perturb and Observe (P\&O) with checking algorithm under various solar irradiation", Solar Energy, Vol. 148, pp. 128-139, 2017.

[10] P. Kofinas, A. Dounis, G. Papadakis, and M. Assimakopoulos, "An Intelligent MPPT controller based on direct neural control for partially shaded PV system", Energy and
Buildings, Vol. 90, pp. 51-64, 2015.

[11] N. Shah and C. Rajagopalan, "Experimental evaluation of a partially shaded photovoltaic system with a fuzzy logic-based peak power tracking control strategy", IET Renewable Power Generation, Vol. 10, No. 1, pp. 98-107, 2016.

[12] Y. Zou, F. Yan, X. Wang, and J. Zhang, “An efficient fuzzy logic control algorithm for photovoltaic maximum power point tracking under partial shading condition", Journal of the Franklin Institute, 2019.

[13] A. Ibrahim, N. Nor, I. Nawi, M. Fakhizan, and K. Mohd, "Genetic algorithm to improve power output of photovoltaic system under partial shaded condition", International Journal of Power Electronics and Drive Systems (IJPEDS), Vol. 10, No. 4, p. 2182, 2019.

[14] C. Basha, V. Bansal, C. Rani, R. Brisilla, and S. Odofin, "Development of Cuckoo Search MPPT Algorithm for Partially Shaded Solar PV SEPIC Converter", Advances in Intelligent Systems and Computing, Vol. 1048, pp. 727736, 2020.

[15] A. Fathy, "Reliable and efficient approach for mitigating the shading effect onphotovoltaic module based on Modified Artificial Bee Colony algorithm", Renewable Energy, Vol. 81, pp. 78-88, 2015.

[16] S. Titri, C. Larbes, K. Toumi, and K. Benatchba, "A new MPPT controller based on the Ant colony optimization algorithm for Photovoltaic systems under partial shading conditions", Applied Soft Computing Journal, Vol. 58, pp. 465-479, 2017.

[17] D. Teshome, C. Lee, Y. Lin, and K. Lian, “A modified firefly algorithm for photovoltaic maximum power point tracking control under partial shading", IEEE Journal of Emerging and Selected Topics in Power Electronics, Vol. 5, No. 2, pp. 661-671, 2017.

[18] D. Debnath, N. Soren, A. Pandey, and N. Barbhuiya, "Improved grey wolf assists MPPT approach for solar photovoltaic system under partially shaded and gradually atmospheric changing condition", International Energy Journal, Vol. 20, No. 1, pp. 87-100, 2020.

[19] A. Eltamaly, M. Al-Saud, and A. Abokhalil, "A Novel Bat Algorithm Strategy for Maximum Power Point Tracker of Photovoltaic Energy Systems Under Dynamic Partial Shading", Open Access Journal, Vol. 8, 2020.

[20] J. Ram and N. Rajasekar, "A Novel Flower Pollination Based Global Maximum Power Point Method for Solar Maximum Power Point 
Tracking”, IEEE Transactions on Power Electronics, Vol. 32, No. 11, pp. 8486-8499, 2017.

[21] T. Nagadurga, P. Narasimham, and V. Vakula, "Global maximum power point tracking of solar PV strings using the teaching learning based optimisation technique", International Journal of Ambient Energy, Vol. 0, No. 0, pp. 1-41, 2020.

[22] J. Fermeiro, J. Pombo, G. Calvinho, and M. Rosário, "Design and implementation of enhanced PSO based MPPT for PV production under partial shading conditions", International Journal of Computing, Vol. 18, No. 4, pp. 381392, 2019.

[23] M. Sarvi, S. Ahmadi, and S. Abdi, "A PSObased maximum power point tracking for photovoltaic systems under environmental and partially shaded conditions", Progress in Photovoltaics: Research and Applications, Vol. 23, No. 2, pp. 201-214, 2015.

[24] Y. Liu, S. Huang, J. Huang, and W. Liang, "A particle swarm optimization-based maximum power point tracking algorithm for PV systems operating under partially shaded conditions", IEEE Transactions on Energy Conversion, Vol. 27, No. 4, pp. 1027-1035, 2012.

[25] R. Venugopalan, T. Babu, N. Rajasekar, and K. Sangeetha, "Modified Particle Swarm Optimization technique based Maximum Power Point Tracking for uniform and under partial shading condition", Applied Soft Computing Journal, Vol. 34, pp. 613-624, 2015.

[26] N. Rajasekar and J. Ram, "A new robust, mutated and fast tracking LPSO method for solar PV maximum power point tracking under partial shaded conditions", Applied Energy, Vol. 5, pp. 45-59, 2017.

[27] H. Li, D. Yang, W. Su, J. Lu, and X. Yu, “An Overall Distribution Particle Swarm Optimization MPPT Algorithm for Photovolt System under Partial Shading", In: IEEE Transactions on Industrial Electronics, Vol. 66, No. 1, pp. 265-275, 2019.

[28] J. Ram, D. Pillai, N. Rajasekar, and S. Strachan, "Detection and Identification of Global Maximum Power Point Operation in Solar PV Applications Using a Hybrid ELPSO-PO Tracking Technique", IEEE Journal of Emerging and Selected Topics in Power Electronics, Vol. 8, No. 2, pp. 1361-1374, 2020.

[29] K. Hu, S. Cao, W. Li, and F. Zhu, "An Improved Particle Swarm Optimization Algorithm Suitable for Photovoltaic Power Tracking under Partial Shading Conditions", IEEE Access, Vol.
7, pp. 143217-143232, 2019.

[30] M. Joisher, D. Singh, S. Taheri, D. Trejo, E. Pouresmaeil, and H. Taheri, "A Hybrid Evolutionary-Based MPPT for Photovoltaic Systems under Partial Shading Conditions", IEEE Access, Vol. 8, pp. 38481-38492, 2020.

[31] R. Motamarri and B. Nagu, "GMPPT by using PSO based on Lévy flight for photovoltaic system under partial shading conditions", IET Renewable Power Generation, Vol. 14, No. 7, pp. 1143-1155, 2020.

[32] R. Prakash and S. Singh, "Designing and Modelling of Solar Photovoltaic Cell and Array", IOSR Journal of Electrical and Electronics Engineering, Vol. 11, No. 2, pp. 3540, 2016.

[33] M. Ramli, S. Twaha, K. Ishaque, and Y. AlTurki, "A review on maximum power point tracking for photovoltaic systems with and without shading conditions", Renewable and Sustainable Energy Reviews, Vol. 67, pp. 144159, 2017.

[34] F. Belhachat and C. Larbes, "Modeling, analysis and comparison of solar photovoltaic array configurations under partial shading conditions", Solar Energy, Vol. 120, pp. 399-418, 2015.

[35] A. Khare and S. Rangnekar, "A review of particle swarm optimization and its applications in Solar Photovoltaic system", Applied Soft Computing Journal, Vol. 13, No. 5, pp. 29973006, 2013.

[36] M. Jiang, Y. Luo, and S. Yang, "Stochastic convergence analysis and parameter selection of the standard particle swarm optimization algorithm", Information Processing Letters, Vol. 102, No. 1, pp. 8-16, 2007.

[37] M. Seyedmahmoudian, S. Mekhilef, R. Rahmani, R. Yusof, and A. Shojaei, "Maximum power point tracking of partial shaded photovoltaic array using an evolutionary algorithm: A particle swarm optimization technique", Journal of Renewable and Sustainable Energy, Vol. 6, No. 2, 2014.

[38] K. Chao, L. Chang, and H. Liu, "Maximum power point tracking method based on modified particle swarm optimization for photovoltaic systems", International Journal of Photoenergy, Vol. 2013.

[39] A. Kamaruzaman, A. Zain, S. Yusuf, and A. Udin, "Levy flight algorithm for optimization problems - A literature review", Applied Mechanics and Materials, Vol. 421, pp. 496501, 2013.

[40] G. Li, Y. Jin, M. Akram, X. Chen, and J. Ji, "Application of bio-inspired algorithms in 
Received: May 26, 2020. Revised: August 21, 2020.

maximum power point tracking for PV systems under partial shading conditions - A review", Renewable and Sustainable Energy Reviews, Vol. 81, No. July 2017, pp. 840-873, 2018. 